DEPARTAMENTO DE ANATOMIA DESCRITIVA DOS ANIMAIS DOMESTICOS Diretor: Prof. Dr. Orlando M. Paiva

\title{
COMPORTAMENTO DA ANSA SPIRALIS DO COI,ON EM OVINOS DA RAÇA CORRIFDALE*
}

\author{
THE ARRANGEMENT OF THE ANSA SPIRALIS OF THE \\ CORRIEDALE SHEEP COLON)
} I. L. DE SANTIS PRADA
Prof Assistente Doutor
VICENTE BORELLI

Prof. Assistente Doutor

JOSE PEDUTI NETO

Prof. Assistente

\section{INTRODUÇÃO E LITERATURA}

Embora KOLDA (1931) tenha presumido serem devidas à idade, as diferenças encontradas no arranjo da ansa spiralis de caprinos e ovinos, SMITH (1957) demonstra, relativamente aos últimos, ser improvável que se modifique o tipo de cólon, uma vez fixado o mesentério ou possa, ainda, o sexo, influenciar-lhe o volteamento. Conhecendo, de outra parte, em carneiros Merino, o grau de enrolamento dessa seç̧ão do intestino grosso (PAIVA \& BORELLI - 1966), bem como a ocorrência de irregularidades na disposição das voltas (BORELLI \& SANTIS PRADA - 1966/67), examinamos, em seguida, o comportamento da alça convoluta em ovinos Corriedale, na tentativa de aferir a possibilidade de interferência do fator raça, nos dois aspectos estudados.

Já nas obras de Anatomia Veterinária, encontramos informaçōes relativas aos variáveis aspectos que pode apresentar a ansa spiralis de caprinos e ovinos. Assim, aludindo ao número de voltas centrípetas, os AA. apontam três (ELLENBERGER \& BAUM - 1932), três a quatro (SCHWARZF \& SCHRÖDER - 1962) e quatro (MARTIN \& SCHAUDER - 1935; SCHUMMER \& NICKEL 1960). Alguns dêles (FLLENBERGER \& BAUM; MARTIN \& SCHAUDER) registram ainda a possibilidade de ocorrência de defeitos a inserirem-se no focado trato intestinal.

Dentre os trabalhos especializados sôbre o assunto desta pes-

- Comunicado ao VIII Congresso Braslleiro de Anatomia. realizado em Pelotas (R8), de 27 a 31 de Julho de 1971 
quisa, o de KOLDA, que mencionamos, assinala três ( 3 cordeiros) e três e meia ( 4 animais menos jovens) voltas de entrada.

Por sua vez, SMITH (1955-a), estudando o segmento convoluto de 1061 carneiros, surpreende $842(79,36 \%)$ com disposiçāo regular das alças a exibirem, relativamente aos giros concêntricos e excêntricos: dois e dois e meio, 2 vêzes $(0,19 \%)$; dois e meio e três, 145 vêzes $(13,67 \%)$; três e três e meio, 516 vêzes $(48,63 \%)$; três e meio e quatro, 173 vêzes $(16,31 \%)$; quatro e quatro e meio, 6 vêzes $(0,57 \%)$. Em $219(20,64 \%)$ intestinos, descobre vícios de conformação inseridos, muitas vêzes $(25,0 \%)$, segundo salienta (1955-b), no último dos giros de saída que, nos ovinos, normalmente se afasta dos mais; nos bovinos, ao contrário, êle não se separa dos restantes da espira, mostrando-se total (SMITH \& MEADOWS - 1956) ou parcialmente (PAIVA \& BORELLI - 1963/64) livre de deformidades.

Em outra publicação, citada de início, SMITH (1957) examina 100 carneiros adultos e 50 fetos revelando, as alças perfeitas dos primeiros, dois e meio ( 8 vêzes), três ( 55 vêzes) e três e meio (19 vêzes) lances proximais.

A seu turno, PAIVA \& BORELLI (1966), já referidos, reunindo $€ m$ seu material de estudo 400 tratos intestinais retirados de carneiros da raça Merino, machos e adultos, classificam os $335(83,75 \%=$ 1,84) fornecedores de cólons regulares, que exibiram: três voltas centrípetas e três e meia centrífugas, 173 vêzes $\left(51,64{ }^{\prime}=2,73\right)$; três e meia e cuatro, 127 vêzes $\left(37,91^{\prime} ;-2,65\right)$; duas e meia e três, 22 vêzes $(6,57$; 1,35$)$; quatro e quatro e meia, 12 vêzes $(3,58 \%$ $\because 1,02)$; quatro e meia e cinco, 1 vez $(0,30 \% 0,30)$. As 65 $\left(16,25{ }^{\prime \prime} \cdot 1,84\right)$ alças irregulares, deixadas à parte, foram depois tipificadas por BORELLI \& SANTIS PRADA, sendo os defeitos considerados como que inseridos em voltas normais, critério, aliás, adotado no exame dos arranjos incomuns da ansa spiralis, ef etuado tanto em bovinos de origem indiana (PAIVA \& BORELLI - 1963/64) ou européia (BORELLI \& PEDUTI - 1966) quanto em caprinos (BORELLI \& FERNANDES - 1965). Nessa pesquisa, BORELLI \& SANTIS PRADA dizem confirmar-se a afirmativa de SMITH (1955-b) já que evidenciam, em $26,15 \%$ das peças, as incorreções localizadas na última e isolada volta do cólon convoluto. Ressaltam, ainda, a grande porcentagem $(17,92 ')$ de irregularidades inseridas no segmento inicial do giro de saída, condição também evidenciada em caprinos (BORELLI \& FERNANDES) que apresentam boa soma $\left(27,14 r^{\prime}\right)$ de defeitos na última alça de saída, a maioria das quais $(21,42 \%)$, no trato proximal dêsse giro. 


\section{MATERIAL E METODO}

Examinamos o cólon convoluto de 100 carneiros machos, adultos, da raça Corriedale, sacrificados no Instituto Butantan, em São Paulo. Inspecionamos as alças pela esouerda, efetuando a contagem das regulares à maneira de SMITH (1955) e registrando o comportamento das irregulares segundo orientação sugerida por PAIVA \& BORELLI $(1963 / 64)$. SMITH conta as alças tomando por pontos de reparo seccões defrontantes da primeira e última curvas, postas sôbre o prolongamento da linha que marca o limite dorsal do cólon convoluto e o centro da espiral, disto decorrendo o registro de meio giro excêntrico a mais. PAIVA \& BORELLI consideram as irregularidades como inseridas em alças normais.

\section{RESULTADOS}

Dentre os 100 tratos intestinais coletados, surpreendemos 93 $(93,0 \% \pm 2,55)$ portadores de cólons regulares, a mostrarem, conforme discriminado no Quadro $I$, os seguintes números de voltas respectivamente de entrada e de saída: duas e meia e três, 6 vêzes $\left(6,45{ }^{\prime} c=2,54\right)$, três e três e meia, 56 vêzes $(60,21 \% \pm 5,07)$, três e meia e quatro, 30 vêzes $(32,26 \%$; $\pm 4,85)$, quatro e quatro e meia, 1 vez $(1,08 \% \div 1,07)$.

Quadro I - Cólon espiral em ovinos da raça Corriedale. machos e adultos, scgundo o numero de giros.

\begin{tabular}{|c|c|c|}
\hline N. de giros & N. ${ }^{\circ}$ de casos & o e desvio padrāo \\
\hline $21,2-3$ & 6 & $6.45 \% \pm 2,54$ \\
$3-31 / 2$ & 56 & $60,21 \% \pm 5,07$ \\
$31 / 2-4$ & 30 & $32,26 \% \pm 4,85$ \\
$4-412$ & 1 & $1,08 \% \pm 1,07$ \\
\hline TOTAL & 93 & $100 \%$ \\
\hline
\end{tabular}

Completando o total das 100 observaçōes, encontramos, afora as 93 peças perfeitas, $7(7,0 \%, 2,55)$ a patentearem alterações no enrolamento. Assim. 1 delas (Fig. 1), com um e um e meio circuitos por ordem, proximal e distais, exibiu defeitc localizado na segunda meia curva centrífuga. Por sua vez, as imperfeições registradas em alças com um e meio e dois giros sucessivamente de entrada e de saída inscreveram-se, 1 vez (Fig. 2), ra segunda meia volta concêntrica e, 1 vez (Fig. 3), na primeira meia curva excêntrica. Em outra espira (Fig. 4), com dois e meio e tris circuitos respectivamente 
centripetos e centrifugos, o desvio instalou-se no quarto meio lance distal. Por fim, evidenciamos as falhas relativas a peças com três arcos a avizinharem-se do centro e três e meio a distanciarem-se dêle, postadas, 1 vez (Fig. 5), na segunda meia curva de entrada e, 2 vêzes (Fig. 6 e 7), nos meios giros excêntricos, isto é, 1 vez (Fig. 6) on terceiro e 1 vez (Fig. 7) no sexto.

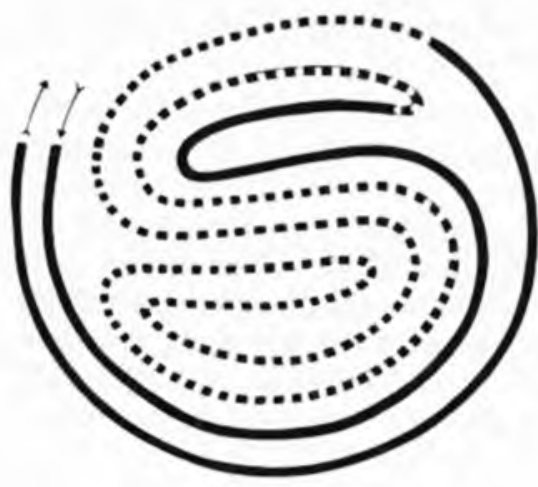

FIg. I

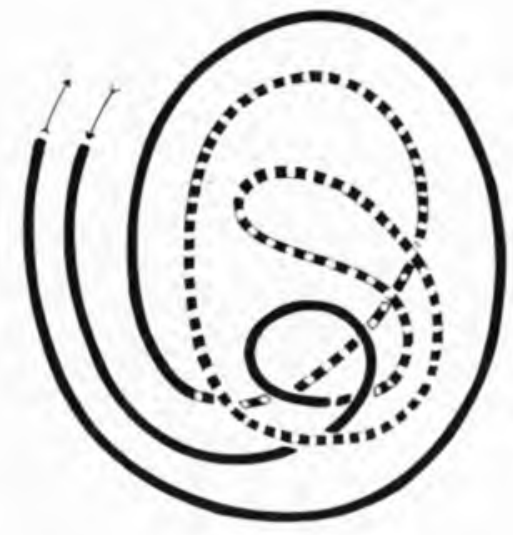

Fyㅏ. 3

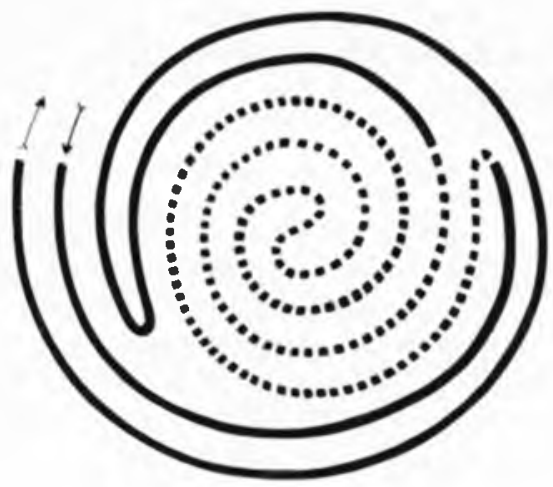

FIg. 2

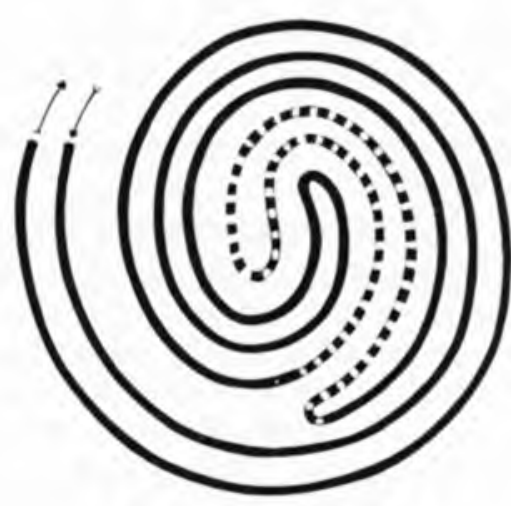

Fig. 4 


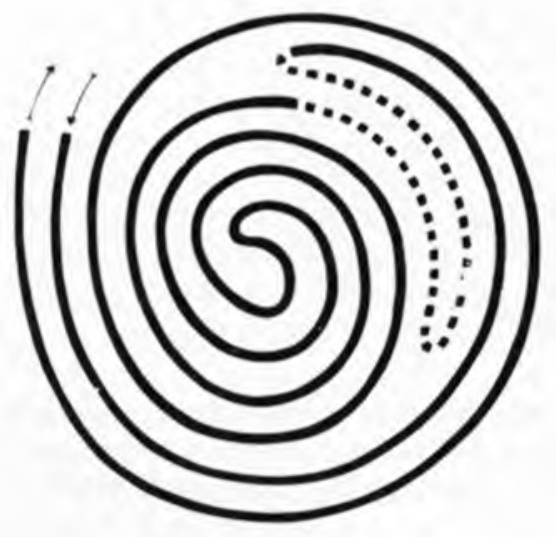

Fig. 5

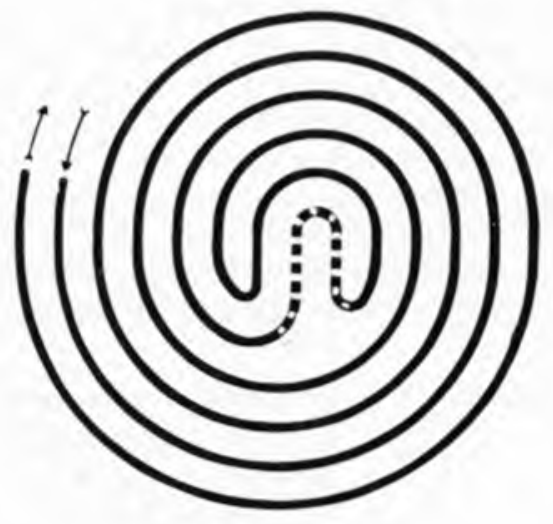

Fig. 6

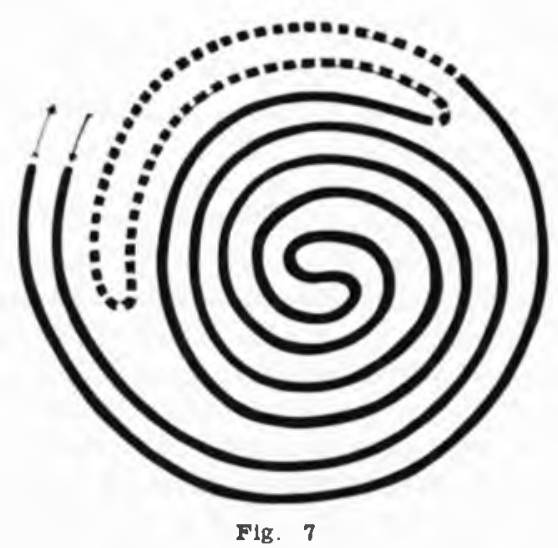

Flgs. 1 a 7 - Essquemas das disposiçóes incomuns da ansa spiralls do collon em ovinos machos, da raça corriedale.

\section{COMENTÃRIOS E CONCLUSŌES}

Uma vez obtidos os dados referentes ao arranjo da ansa spiralis em carneiros Corriedale, no que diz respeito tanto ao grau de enrolamento dessa secção do intestino grosso quanto à ocorrência de irregularidades na disposição das voltas, interessa-nos de pronto confrontá-los com as informações contidas nos trabalhos de PAIVA \& BORELLI $(1963 / 64)$ e BORELLI \& SANTIS PRADA, que cuidam do comportamento da alça convoluta em ovinos Merino, já que era nosso propósito, desde o início, aferir a possibilidade de interferência do fator raça nos dois aspectos estudados. Particularizando, de começo, o arranjo dos tratos intestinais perfeitos, nos dois grupos de animais, ressaltamos logo que é coincidente a sequência dos prin- 
cipais tipos de espiras a exibirem, em ordem decrescente, três, três e meio, dois e meio e, por fim, quatro circuitos proximais; deixamos de mencionar a classe quatro e meio, que ocuparia o último lugar na precedente citação, pelo fato de não ter ocorrido, em nosso material - contràriamente ao observado por PAIVA \& BORELLI $(1963 / 64)$ em $30,0 \%$ dos casos - o encontro de alças a descreverem tal número de voltas concêntricas. O cotejo direto (Quadro II) das frequências encontradas na publicação dêstes AA. com as que assinalamos, não revelou diferença estatisticamente significante, ao nivel de $5 \%$.

Quadro II - Frequências observadas e esperadas, relativamente ao número de giros da alça espiral, em carneiros, admitindo-se para nossa amostra a distribuição percentual estabelecida por PAIVA \& BORELI (1963/64).

\begin{tabular}{|c|c|c|}
\hline Frequências & Observadas & Esperadas \\
\hline No de giros & 6 & 6,11 \\
\hline $21 / 2-3$ & 56 & 48,03 \\
$3-31 / 2$ & 30 & 35,26 \\
$31 / 2-4,33$ \\
$41 / 2$ & 1 & 0,27 \\
$41 / 2-5$ & 0 & 93 \\
\hline
\end{tabular}

Ainda no tocante aos aspectos normais da ansa spiralis, esclarecemos não possibilitarem discussão com os nossos resultados, as restritas informações exaradas por KOLDA e pelos tratadistas consultados (ELLENBERGER \& BAUM; SCHWARZE \& SCHRÖDER; MARTIN \& SCHAUDER; SCHUMMER \& NICKEL). Já os trabalhos de SMITH $(1955-a, 1957)$, embora não discriminem a raça dos animais estudados, permitem-nos algumas considerações. Assim, registramos, como êle, e com idêntica ordenação de frequências, a maior parte das modalidades de disposições regulares do cólon convoluto (três, três e meio, dois e meio e quatro giros de entrada). Entretanto, SMITH (1955-a) relata, ainda, ocorrência de espiras com dois lances proximais, fato que, como PAIVA \& BORELLI (1966), não assinalamos; por outro lado, como nós, não ençontra alças com quatro e meia voltas concêntricas, surpreendidas por aquêles AA., se bem que em baixa porcentagem $(0,30 \%)$.

Focalizando, a seguir, as disposições incomuns da secção espiralada do intestino grosso, esclarecemos que, no cotejo dos nossos dados com os da literatura consultada, dentre êstes, revestem-se de maior importância, pelo motivo já exposto, os referidos em publi- 
cação anterior (BORELLI \& SANTIS PRADA). Aliás, também agora classificamos os defeitos à maneira de PAIVA \& BORELLI $(1963 / 64)$, critério adotado posteriormente por BORELLI \& PEDUTI e BORELLI \& FERNANDES. Das 7 peças anômalas que descobrimos nos ovinos Corriedale, 6 exibiram desenhos dos quais encontramos similares entre as irregularidades tipificadas por BORELLI \& SANTIS PRADA, em carneiros Merino. Cumpre-nos também salientar que, dentre as 7 espiras anormais, 2 (Figs. 1, 7) apresentaram a anomalia inserida na porção inicial da última volta de saída, anotação concordante com a afirmativa de SMITH (1955-b), por sua vez alicerçada no fato de ter observado, em ovinos, os vícios de conformação instalados, muitas vêzes $(25,0 \%)$, no último dos giros cxcêntricos, normalmente afastado dos mais, contràriamente ao veriIicado nos bovinos, onde êle não se afasta dos restantes da alça convoluta, mostrando-se total (SMITH \& MEADOWS) ou parcialmente (PAIVA \& BORELLI 1963/64) livre de deformidades. Essa informação de SMITH, diga-se de passagem, já havia sido confirmada por BORELII \& SANTIS PRADA ao evidenciarem, em $26,15 \%$ das peças examinadas, as incorreçóes localizadas na última e isolada curva do cólon espiralado. Conforme ressaltam, grande porcentagem dessas espiras $\left(17,92^{\prime} \prime\right.$ ) exibiram as irregularidades postadas no segmento proximal da aludida volta centrífuga, condição descoberta nos 2 casos relatados, constantes de nosso material e, ainda, anteriormente, em caprinos (BORELLI \& FERNANDES) que mostram boa soma $(27,14 \%)$ de defeitos no último arco distal, a maioria dos quais $(21,42 \%)$, na primeira metade dêsse giro. Assinalamos, finalmente, que não surpreendemos a ocorrência simultânea de dois defeitos em uma mesma peça, tal como se nota, 2 vêzes, nas figuras do trabalho de BORELLI \& SANTIS PRADA.

\section{SUMMARY}

An analysis of the arrangement of the ansa spiralis of 100 Corriedale sheep colons showed that $93\left(93,0 r_{i} \pm 2,55\right)$ had regular patterns: $56(60,21 \%-5,07)$ were seen with three centripetal and three and a half centrifugal coils, $30(32,26 \% \pm 4,85)$ with three and a half centripetal and four centrifugal coils, $6(6,45 \% \pm 2,54)$ with two and a half centripetal and three centrifugal coils and 1 $(1,08 \% \pm 1,07)$ with four centripetal and four and a half centrifugal coils; the remaining 7 colons $(7,0 \% \pm 2,55)$ were observed with irregular spirals.

\section{REFERENCIAS BIBLIOGRAFICAS}

BORELLI, V. \& FERNANDES FILHO, A. - Irregularidades da ansa spiralis do cólon em caprinos. Rev. Fac. Med. vet., S. Paulo, 7 (2): 319-323, 1965. 
BORELLI, V. \& PEDUTI NETO, J. - Comportamento da ansa spiralis em bovinos de origem européia. Rev. Med. vet., S. Paulo, 2: 52-57, 1966.

BORELLI, V. \& SANTIS PRADA, I. L. - Irregularidades da ansa spiralis do cólon em ovinos de raça Merino. Rev. Fac. Med. vet., S. Paulo, y (3): 521-526, 1966/67.

ELLENBERGER, W. \& BAUM, H. - Handbuch der vergleichenden Anatomie der Haustiere. v.1. 17 Auf. Berlin, Julius Springer, 1932.

KOLDA, J. - Zur Topographie des Darmes bein Schaf und bei der Ziege. Z. Anat. Entwgesch, Berlim, 95: 243-269, 1931.

MARTIN, P. \& SCHAUDER, W. - Lehrbuch der Anatomie der Haustiere. Bd. 3, h 2., 3 auf Stuttgart, Verlag von Schickhard \& Ebner, 1935.

PAIVA, O. M. \& BORELLI, V. - Disposiçōes incomuns da ansa spiralis do cólon em bovinos azebuados. Rev. Fac. Med. vet., S. Paulo, 7 (1): 11-17, $1963 / 64$

PAIVA, O. M. \& BORELLI, V. - Comportamento da ansa spiralis do cólon em ovinos. Folia clin. biol., S. Paulo, 35: 57-61, 1966.

SCHUMMER, A. \& NICKEL, R. - In NICKEL, R.; SCHUMMER, A. \& SEIFERLE, E. - Lehrbuch der Anatomie der Haustiere. v. 2. Berlin, Paul Parey, 1960.

SCHWARZE, E. \& SCHRÖDER, L., - Kompendium der Veterinär-anatomie. v.2. Jena, Gustav Fischer, 1962.

SMITH, R. N. - The arrangement of the ansa spiralis of the sheep colon. J. Anat., London, 89 (2): 246-249, 1955-a.

SMITH, R. N. - Further observations on the colon primum of the sheep. J. Anat., London, 89 (4): 579, 1955-b.

SMITH, R. N. - The pattern of the ansa spiralis of the sheep colon. (a) does it change? (b) is it influenced by the sex of the sheep? Br. vet. J., London, 113 (12): 501-503, 1957.

SMITH, R. N. \& MEADOWS, G. W. - The arrangement of the ansa spiralis of the ox colon. J. Anat., London, 90 (4): 523-526, 1956. 